\section{Commentary on: Dental patients' use of the Internet}

\author{
R. M. Ní Ríordáin and C. McCreary
}

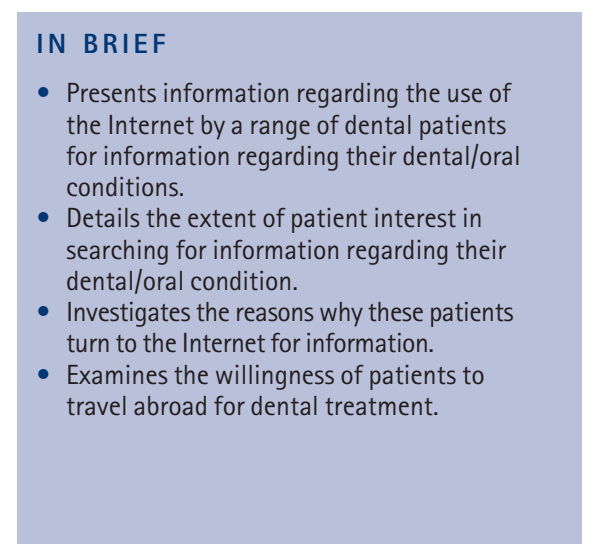

\begin{abstract}
Aims and objectives To determine the use of the Internet by patients attending a range of dental clinics to search for information regarding dental procedures, and also to investigate their interest in online dental consultations and 'dental tourism.' Methods A questionnaire was designed and randomly distributed to 520 patients attending the restorative dentistry, dental surgery and oral medicine clinics of Cork University Dental School and Hospital. Results Of the 520 questionnaires distributed, 500 were completed leading to a response rate of 96.2\%. The majority of patients were familiar with using the Internet on a daily basis, with only 163 (32.6\%) patients not using the Internet in their everyday lives. One hundred and seventy-seven (34.5\%) patients either researched their presenting dental/oral condition or had a family or friend research their condition on their behalf. One hundred and eighty-five (37\%) patients would consult with a dental practitioner online regarding an oral problem and a similar number $(n=186)$ of patients surveyed would consider using the Internet to plan trips abroad for dental treatment. Conclusion Practitioner-led direction for patients regarding quality information sources online is important. With the increased interest in travelling abroad for dental treatment, guidance for patients and practitioners regarding the legal and ethical issues pertaining to dental tourism is critical.
\end{abstract}

\section{COMMENTARY}

The evolution of the Internet has enabled the public to view vast reserves of information at the click of a computer mouse, to the extent that access to medical and dental information is no longer the sole preserve of health professionals. As a result, the Internet has the potential to educate and empower the dental consumer by providing information on oral health services and by supporting self-help and patient choice.

While most clinicians are now familiar with patients enquiring about information they have gleaned from the Internet, the degree to which this occurs remains relatively unquantified. The current study, based in Cork University Dental School and Hospital, set out to determine the use of the Internet by patients attending a range of specialist clinics and the degree to which patients searched for information regarding dental procedures or were interested in online dental consultations and 'dental tourism'.

While one third of patients did not make everyday use of the Internet, one in three of those participating in the survey had either researched their own dental/ oral condition or had a family member or friend do so on their behalf. Patients attending oral medicine clinics were significantly more likely to have researched their condition online than those attending other specialist clinics. Again, one in three patients indicated that they would consult with a dentist online (including practices based abroad). Those with access to the Internet at home and higher educational attainment were more likely to have accessed information this way.

The study was conducted in a dental hospital, with presumably a large number of referred patients, so the results cannot be extrapolated to the general population. Nevertheless, it demonstrates the increasingly all-pervasive nature of the Internet and serves as a timely reminder for those responsible for the organisation and delivery of dental services: that they should take care to ensure that the potential of the Internet is exploited to the maximum, while taking steps to inform, guide and protect patients from the information jungle that it represents.

\section{G. Chestnutt}

Professor and Honorary Consultant in Dental Public Health,

Cardiff University School of Dentistry DOI: 10.1038/sj.bdj.2009.1158 